\title{
Short and Efficient Syntheses of Protoberberine Alkaloids using Palladium-Catalyzed Enolate Arylation**
}

\author{
Alice E. Gatland, Ben S. Pilgrim, Panayiotis A. Procopiou, and Timothy J. Donohoe*
}

\begin{abstract}
A concise synthesis of the biologically active alkaloid berberine is reported, and a versatile palladiumcatalyzed enolate arylation is used to form the isoquinoline core. The overall yield of $50 \%$ is a large improvement over the single, previous synthesis. By design, this modular route allows the rapid synthesis of other members of the protoberberine family (e.g., pseudocoptisine and palmatine) by substitution of the readily available aryl bromide and ketone coupling partners. Moreover, by combining enolate arylation with in situ functionalization, substituents can be rapidly and regioselectively introduced at the alkaloid C13 position, as demonstrated by the total synthesis of dehydrocorydaline. The avoidance of electrophilic aromatic substitution reactions to make the isoquinoline allows direct access to analogues possessing more varied electronic properties, such as the fluorine-containing derivative synthesized here.
\end{abstract}

$T_{\text {he isoquinoline skeleton is one of the most prevalent core }}$ structures in alkaloid natural product chemistry. A subdivision of this class is the protoberberine alkaloids, an important group of secondary metabolites possessing significant biological activities as a result of their ability to bind or intercalate DNA. ${ }^{[1]}$ Isolated from an extensive range of plants, all members feature a 5,6-dihydrodibenzo[a,g]quinolizinium moiety (the protoberberine skeleton), typically functionalized with hydroxy, methoxy, and methylenedioxy substituents. The parent compound, berberine (Scheme 1), is the most widely distributed and intensely studied of such alkaloids, thus having demonstrated antifungal, antibacterial, antiinflammatory, antimalarial, antidiabetic, and anticancer activity. ${ }^{[1,2]}$ Yet it has seen only one previous total synthesis, by Kametani and co-workers in 1969, which provided berberine iodide in low yield from a commercially unavailable starting

[“] A. E. Gatland, Dr. B. S. Pilgrim, Prof. T. J. Donohoe Department of Chemistry, University of Oxford Chemistry Research Laboratory

Mansfield Road, Oxford, OX1 3TA (UK)

E-mail: timothy.donohoe@chem.ox.ac.uk

Dr. P. A. Procopiou

GlaxoSmithKline Medicines Research Centre

Gunnels Wood Road, Stevenage, SG1 2NY (UK)

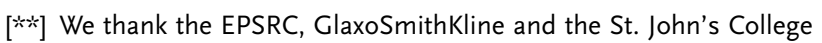
Oxford for financial support.

2) Supporting information for this article is available on the WWWW under http://dx.doi.org/10.1002/anie.201409164.

of (C) 2014 The Authors. Published by Wiley-VCH Verlag GmbH \& Co. $\mathrm{KGaA}$. This is an open access article under the terms of the Creative Commons Attribution License, which permits use, distribution and reproduction in any medium, provided the original work is properly cited.

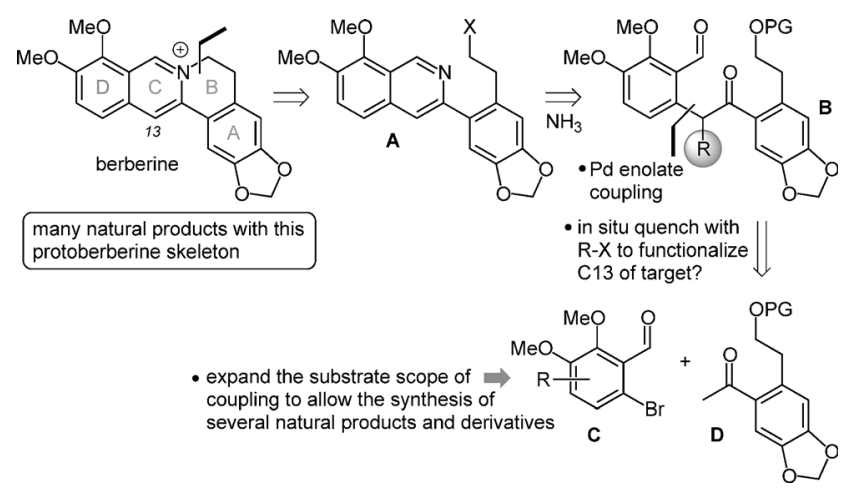

Scheme 1. Retrosynthesis of berberine and skeletally related protoberberine natural products. $\mathrm{PG}=$ protecting group.

material. ${ }^{[3]}$ The majority of synthetic approaches to related compounds rely on electrophilic aromatic substitution to form the central rings. Whilst this allows access to analogues with electron-rich scaffolds, those with more varied electronic properties are not readily accessible.

As we have previously reported, recent work in our laboratories has culminated in the development of a versatile method for the synthesis of isoquinolines. ${ }^{[4]}$ This protocol employed the palladium-catalyzed $\alpha$-arylation ${ }^{[5]}$ of readily available ketones (using aryl bromides bearing an orthoacetal) to generate masked 1,5-dicarbonyl intermediates, which could be cyclized with a source of $\mathrm{NH}_{3}$ to provide an extensive array of isoquinolines in excellent yields. ${ }^{[6]} \mathrm{We}$ therefore sought to apply this approach to the short total synthesis of berberine and related targets. Furthermore, an extension of our initial isoquinoline-forming methodology introduced functional groups at the $\mathrm{C} 4$ position of the isoquinoline skeleton. ${ }^{[7]}$ This method exploited the fact that the product of enolate arylation is more acidic than the starting ketone and therefore exists as an enolate in the reaction mixture before quenching. Consequently, this enolate may be trapped in situ by a variety of alkyl, allyl, benzyl, and heteroatom electrophiles, ${ }^{[8]}$ and these are carried through to occupy the $\mathrm{C} 4$ position in the resulting isoquinoline. It was anticipated that this highly effective methodology would be well suited to the introduction of substituents at $\mathrm{C} 13$ in the protoberberine alkaloids (Scheme 1). It was envisaged that subsequent formation of the $\mathrm{B}$ ring of berberine could be achieved through nucleophilic displacement of the leaving group $\mathrm{X}$ (anticipated to be chloride) by the isoquinoline nitrogen atom. ${ }^{[9]}$ The isoquinoline $\mathbf{A}$ in question would be generated by aromatization of the dicarbonyl compound $\mathbf{B}$, which is the product of a palladium-catalyzed coupling 


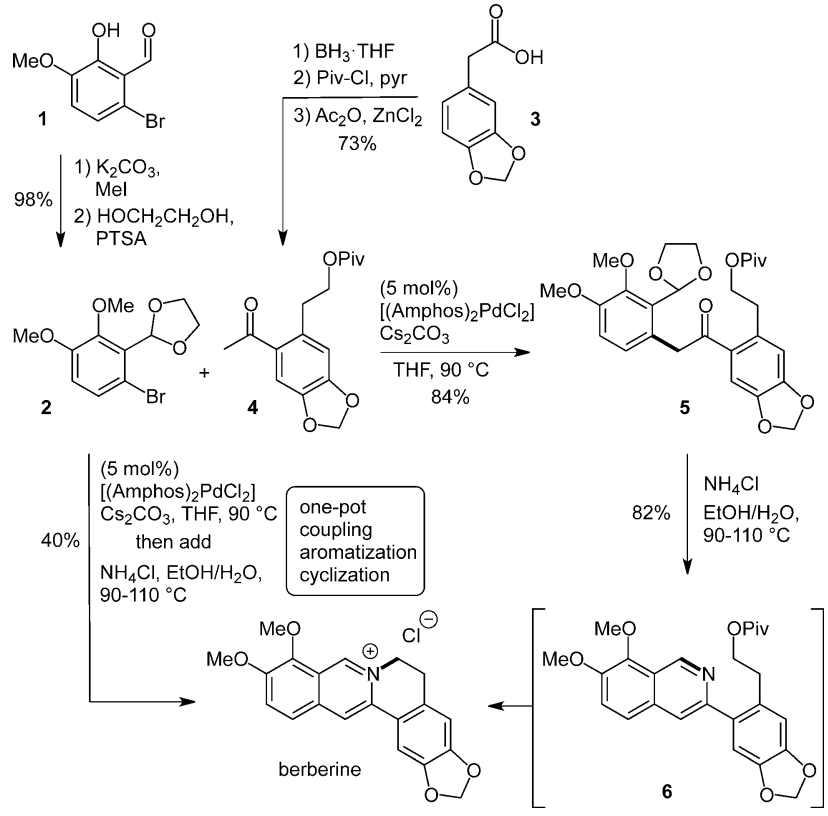

Scheme 2. Synthesis of berberine by a sequential enolate coupling, aromatization, and cyclization sequence. Piv = pivaloyl, PTSA $=$ paratoluenesulfonic acid, $\mathrm{pyr}=$ pyridine, $\mathrm{THF}=$ tetrahydrofuran.

between the aryl bromide $\mathbf{C}$ and the enolate of ketone $\mathbf{D}$. Trapping of the product enolate with an alkyl halide in situ would install a functional group (R) at C13.

The synthesis of berberine commenced with the preparation of the aryl bromide $\mathbf{2}$ by methylation and acetal protection of the commercially available benzaldehyde $\mathbf{1}$ in $98 \%$ yield over two steps (Scheme 2). Its coupling partner, $\mathbf{4}$, was accessed by $\mathrm{BH}_{3}$ reduction of the commercially available acid $\mathbf{3}$ and subsequent protection of the free alcohol as the pivaloate ester. Regioselective Friedel-Crafts acylation using $\mathrm{Ac}_{2} \mathrm{O}$ and $\mathrm{ZnCl}_{2}$ afforded 4 in $73 \%$ yield over three steps.

With the easily accessible coupling partners $\mathbf{2}$ and $\mathbf{4}$ in hand, the key catalytic $\alpha$-arylation step was investigated. The ketone 4 was found to be unstable in the presence of $\mathrm{NaO} t \mathrm{Bu}$, but pleasingly, the milder base $\mathrm{Cs}_{2} \mathrm{CO}_{3}$, in combination with $5 \mathrm{~mol} \%$ [(Amphos $\left.)_{2} \mathrm{PdCl}_{2}\right]$, facilitated coupling to provide $\mathbf{5}$ in an excellent yield of $84 \%$. Note that the reaction was performed in a sealed vial to allow temperature elevation to $90^{\circ} \mathrm{C}$, and to achieve full conversion of the aryl bromide it was necessary here (and in the following arylations) to use two equivalents of the ketone, which could be recovered easily after the reaction was complete. However, the product 5 could still be obtained in very good yield ( $74 \%)$ when using just 1.2 equivalents of 4 .

As anticipated, treating 5 with $\mathrm{NH}_{4} \mathrm{Cl}$ in $\mathrm{EtOH} / \mathrm{H}_{2} \mathrm{O}$ at $90{ }^{\circ} \mathrm{C}$ effected hydrolysis of the acetal and subsequent aromatization to provide the desired isoquinoline 6. However, upon workup, the characteristic bright yellow color of berberine was obvious in the aqueous phase, thus indicating partial displacement of pivaloate by the isoquinoline nitrogen atom. This reactivity was therefore exploited to negate the need for pivaloate ester cleavage and hydroxy activation. Following formation of $\mathbf{6}$ from $\mathbf{5}$, the direct displacement of pivaloate was promoted simply by increasing the reaction temperature from $90^{\circ} \mathrm{C}$ to $110^{\circ} \mathrm{C}$, to give a smooth one-pot conversion into berberine in $82 \%$ yield. Pure berberine chloride was obtained by adding $\mathrm{NaOH}$ to convert the isoquinolinium salt into its hydroxide adduct which was extracted with $\mathrm{CH}_{2} \mathrm{Cl}_{2} \cdot{ }^{[1]}$ Subsequent treatment with $\mathrm{HCl}$ regenerated the chloride salt.

Furthermore, the miscibility of THF, EtOH, and $\mathrm{H}_{2} \mathrm{O}$ permitted one-pot enolate arylation, isoquinoline formation, and cyclization of the $\mathrm{B}$ ring, thus providing berberine chloride from 2 and 4 in $40 \%$ yield (equivalent to $74 \%$ per step). Hence, the synthesis of berberine chloride was achieved in an overall yield of $68 \%$ from compound 1 (the most valuable starting material) or $50 \%$ from compound $\mathbf{3}$ (the longest linear sequence).

A key and advantageous feature of this modular route is the ability to access structurally diverse alkaloids simply by varying the aryl bromide and/or ketone coupling partners. This modularity is exemplified in the synthesis of pseudocoptisine by an identical route to that used for berberine, but starting from the alternative aryl bromide 7 (Scheme 3).

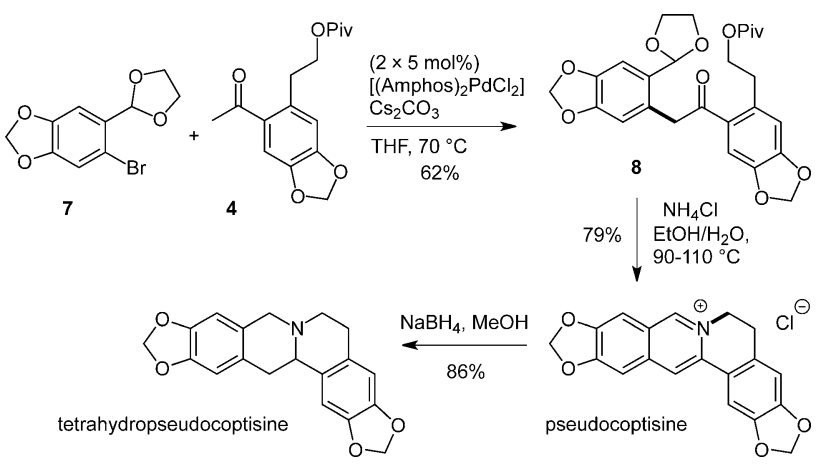

Scheme 3. Synthesis of pseudocoptisine.

Pseudocoptisine has been shown to inhibit acetylcholinesterase and possesses cognitive enhancing anti-amnesic properties. ${ }^{[10]}$ One other synthesis has been reported, which invloves a photochemical enamide cyclization to form the $\mathrm{C}$ ring. ${ }^{[11]}$

While previously reported NMR data for pseudocoptisine were obtained in $\mathrm{CDCl}_{3}{ }^{[10]}$ we found our material to be insoluble in this solvent, as had others. ${ }^{[12]}$ Data were obtained in both $\left[\mathrm{D}_{6}\right] \mathrm{DMSO}$ and $\mathrm{CD}_{3} \mathrm{OD}$ but a close match with literature data in $\mathrm{CD}_{3} \mathrm{OD}^{[13]}$ was not made (this may be attributable to a difference in counterion, which is not described in the literature). Therefore, a known precursor and a tetrahydro derivative of pseudocoptisine were also synthesized separately (see the Supporting Information for details) $\cdot{ }^{[9,14]}$ The ${ }^{1} \mathrm{H}$ and ${ }^{13} \mathrm{C}$ NMR data for these compounds were in agreement with those previously reported, and COSY, HSQC, and HMBC analyses of our synthetic pseudocoptisine were fully consistent with the published structure.

Our attention turned to the total synthesis of the C13methylated protoberberine dehydrocorydaline, ${ }^{[15]}$ which has previously been prepared once before ${ }^{[16]}$ and also semisynthesized by methylation of palmatine (Scheme 4) ${ }^{[17]}$ It was anticipated that the application of in situ enolate functional- 


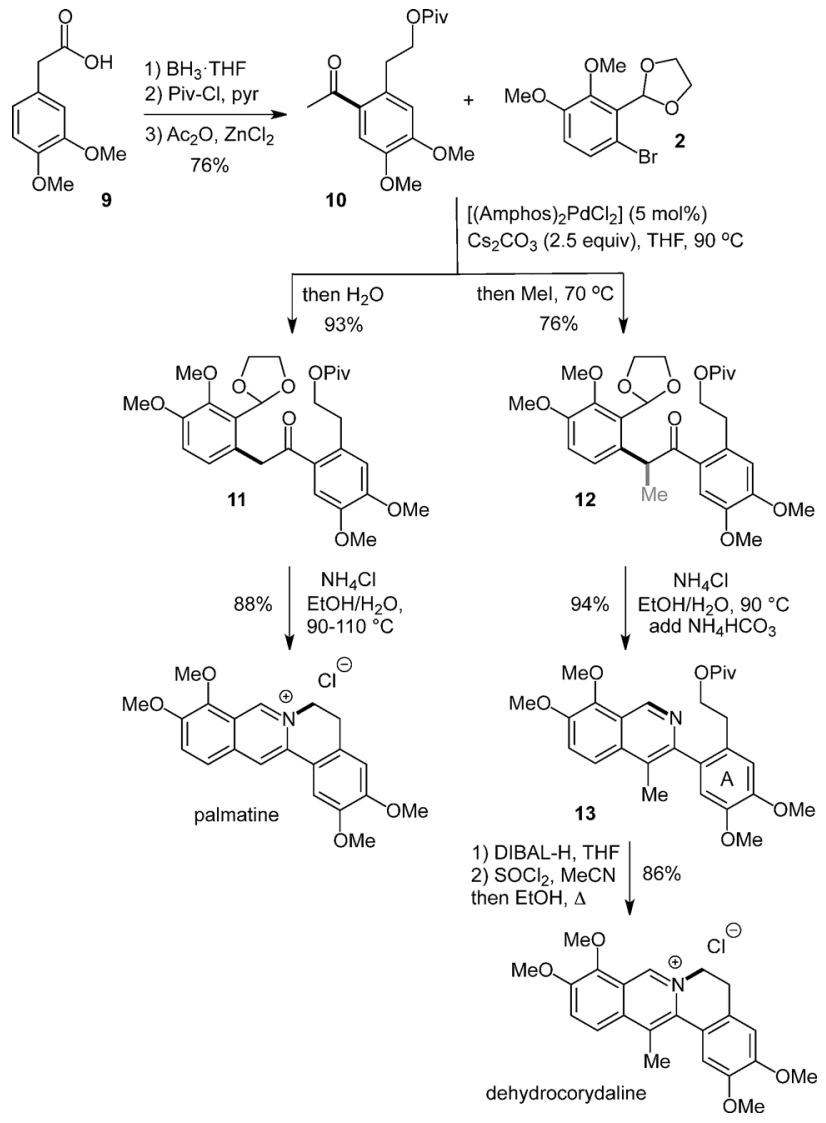

Scheme 4. Palladium-catalyzed enolate coupling with in situ enolate derivatization using methyl iodide. DIBAL = diisobutylaluminum hydride

ization methodology would allow the rapid introduction of this methyl group following enolate arylation. ${ }^{[7]}$

Before exploring this route, however, it was necessary to obtain the appropriate ketone coupling partner 10, which was accomplished in $76 \%$ overall yield by reduction, protection, and regioselective Friedel-Crafts acylation of the corresponding acid $\mathbf{9}$ (Scheme 4). The coupling of ketone $\mathbf{1 0}$ and aryl bromide 2 required no optimization, and was successful under identical reaction conditions to those used in the synthesis of berberine, thus highlighting the flexibility and synthetic utility of this route. Quenching the reaction with water provided the ketone $\mathbf{1 1}$ in $93 \%$ yield, and in a single step, could be efficiently converted into the alkaloid palmatine in $88 \%$ yield by our one-pot aromatization/cyclization protocol. ${ }^{[18]}$ Pleasingly, as anticipated, in situ functionalization of the arylation product could easily be achieved through the addition of MeI to the reaction mixture, thus providing the $\alpha$-methylated ketone $\mathbf{1 2}$ in $76 \%$ yield.

Surprisingly at first, subjecting the masked 1,5-dicarbonyl $\mathbf{1 2}$ to the aromatization/cyclization conditions $\left(\mathrm{NH}_{4} \mathrm{Cl}, \mathrm{EtOH} /\right.$ $\mathrm{H}_{2} \mathrm{O}, 90-110^{\circ} \mathrm{C}$ ) did not facilitate a one-pot conversion into dehydrocorydaline (Scheme 4). It is likely that the presence of the C4-methyl group in the isoquinoline $\mathbf{1 3}$ restricts rotation about the isoquinoline-aryl bond, thereby disfavoring the near planar conformation required for displacement of pivaloate by the nitrogen atom. This hypothesis is supported by the ${ }^{1} \mathrm{H}$ NMR spectrum of $\mathbf{1 3}$, in which the $\mathrm{CH}_{2}$ protons adjacent to the A ring are diastereotopic. Reverting to our original proposal for protoberberine synthesis, $\mathbf{1 3}$ could be isolated in $94 \%$ yield by the treating precursor $\mathbf{1 2}$ first with $\mathrm{NH}_{4} \mathrm{Cl}$, which gave a mixture of $\mathbf{1 3}$ and an isochromene side product (see the Supporting Information for details), then basification with $\mathrm{NH}_{4} \mathrm{HCO}_{3}$ and further heating to convert the isochromene into 13. To introduce a more effective leaving group and so increase the rate of cyclization, the pivaloate ester was removed by DIBAL-H reduction. Transformation of the alcohol to the chloride by the action of $\mathrm{SOCl}_{2}$ in $\mathrm{MeCN}$, with subsequent solvent exchange and heating afforded dehydrocorydaline chloride in $86 \%$ yield over three steps, and hence an overall yield of $47 \%$ for the total synthesis. The spectroscopic data for this compound were a good match with those reported for the natural product. ${ }^{[15 a, c]}$

Finally, the scope of this methodology was tested in the preparation of an unnatural, fluorinated, protoberberine analogue (16) by coupling the ketone $\mathbf{4}$ with aryl bromide 14 in $74 \%$ yield (Scheme 5). The ability to access such

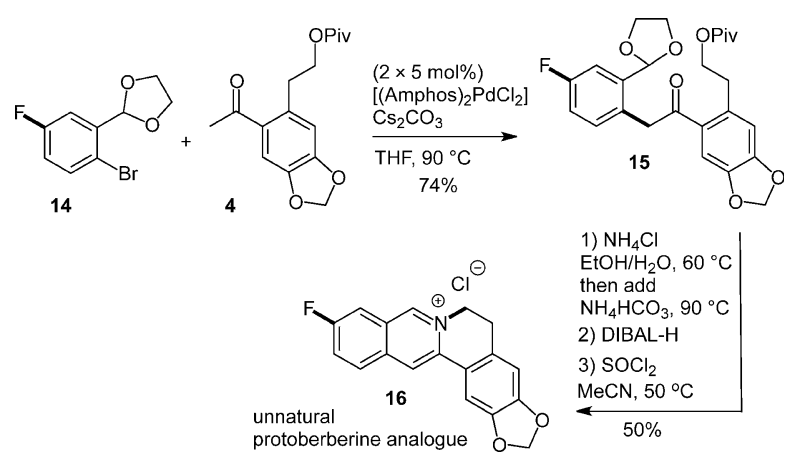

Scheme 5. Formation of a fluorinated, unnatural analogue.

analogues, with tunable electronic and steric properties, is potentially important from a medicinal chemistry perspective, particularly those that do not contain solely electron-rich aromatic rings. The susceptibility of the fluorinated isoquinoline core to decomposition, presumably by nucleophilic aromatic substitution, necessitated mild reaction conditions for formation of the $\mathrm{B}$ and $\mathrm{C}$ rings from $\mathbf{1 5}$. To this end, acetal cleavage was conducted at $60^{\circ} \mathrm{C}$, followed by in situ aromatization at $90^{\circ} \mathrm{C}$, and conversion of the pivaloate ester into a chloride leaving group in the manner described for dehydrocorydaline. Nucleophilic displacement of chloride by nitrogen followed rapidly in the same vessel, with no need for solvent exchange or elevation of temperature. The unnatural analogue $\mathbf{1 6}$ was obtained in $50 \%$ yield over this sequence from $\mathbf{1 5}$.

To conclude, berberine chloride was synthesized by a fivestep (longest linear sequence) route in $50 \%$ overall yield. This synthesis features a flexible palladium-catalyzed enolate arylation as the key step, and hence by substitution of the aryl bromide and ketone coupling partners, analogous syntheses of pseudocoptisine and palmatine (in 36\% and $62 \%$ yields respectively), and of an unnatural fluorinated analogue (in $27 \%$ yield) were readily achieved. Finally, 
enolate arylation was combined with in situ methylation to allow rapid derivatization of the alkaloid $\mathrm{C} 13$ position, thus resulting in the total synthesis of dehydrocorydaline in $47 \%$ yield.

Received: September 16, 2014

Published online: October 27, 2014

Keywords: alkaloids · natural products - palladium . synthetic methods · total synthesis

[1] a) L. Grycová, J. Dostál, R. Marek, Phytochemistry 2007, 68 150; b) K. Bhadra, G. S. Kumar, Med. Res. Rev. 2011, 31, 821

[2] a) Y. Xu, Y. Wang, L. Yan, R.-M. Liang, B.-D. Dai, R.-J. Tang, P.H. Gao, Y.-Y. Jiang, J. Proteome Res. 2009, 8, 5296; b) F. R. Stermitz, P. Lorenz, J. N. Tawara, L. A. Zenewicz, K. Lewis, Proc. Natl. Acad. Sci. USA 2000, 97, 1433; c) C.-L. Kuo, C.-W Chi, T.-Y. Liu, Cancer Lett. 2004, 203, 127; d) K. Iwasa, H.-S Kim, Y. Wataya, D.-U. Lee, Eur. J. Med. Chem. 1998, 33, 65; e) H. Zhang, J. Wei, R. Xue, J.-D. Wu, W. Zhao, Z.-Z. Wang, S.K. Wang, Z.-X. Zhou, D.-Q. Song, Y.-M. Wang, H.-N. Pan, W.-J. Kong, J.-D. Jiang, Metabolism 2010, 59, 285; f) J. B. Kim, J. H. Yu, E. Ko, K. W. Lee, A. K. Song, S. Y. Park, I. Shin, W. Han, D. Y. Noh, Phytomedicine 2010, 17, 436; g) T. Serafim, P. Oliveira, V. Sardao, E. Perkins, D. Parke, J. Holy, Cancer Chemother. Pharmacol. 2008, 61, 1007.

[3] a) T. Kametani, I. Noguchi, K. Saito, S. Kaneda, J. Chem. Soc. C 1969, 2036; see also, b) H. Ishii, M. Ozawa, S. Ohta, T. Harayama, T. Ishikawa, Heterocycles 1994, 37, 897; For examples of the synthesis of berberine analogues and modification of berberine itself see, c) P. Yang, D.-Q. Song, Y.-H. Li, W.-J. Kong, Y.-X. Wang, L.-M. Gao, S.-Y. Liu, R.-Q. Cao, J.-D. Jiang, Bioorg. Med. Chem. Lett. 2008, 18, 4675; d) K. Iwasa, M. Kamigauchi, M Ueki, M. Taniguchi, Eur. J. Med. Chem. 1996, 31, 469.

[4] T. J. Donohoe, B. S. Pilgrim, G. R. Jones, J. A. Bassuto, Proc. Natl. Acad. Sci. USA 2012, 109, 11605.

[5] a) M. Palucki, S. L. Buchwald, J. Am. Chem. Soc. 1997, 119, 11108; b) B. C. Hamann, J. F. Hartwig, J. Am. Chem. Soc. 1997, 119, 12382; c) T. Satoh, Y. Kawamura, M. Miura, M. Nomura, Angew. Chem. Int. Ed. Engl. 1997, 36, 1740; Angew. Chem. 1997, 109, 1820; for reviews see, d) G. C. Lloyd-Jones, Angew. Chem. Int. Ed. 2002, 41, 953; Angew. Chem. 2002, 114, 995; e) C. C. C. Johansson, T. J. Colacot, Angew. Chem. Int. Ed. 2010, 49, 676; Angew. Chem. 2010, 122, 686; f) F. Bellina, R. Rossi, Chem. Rev. 2010, 110, 1082.

[6] For selected isoquinoline syntheses and application to natural product synthesis, see: a) G. Dai, R. C. Larock, J. Org. Chem. 2003, 68, 920; b) Z. Xiang, T. Luo, K. Lu, J. Cui, X. Shi, R. Fathi,
J. Chen, Z. Yang, Org. Lett. 2004, 6, 3155; c) R. P. Korivi, C.-H. Cheng, Org. Lett. 2005, 7, 5179; d) C. D. Gilmore, K. M. Allan, B. M. Stoltz, J. Am. Chem. Soc. 2008, 130, 1558; e) K. M. Allan, B. M. Stoltz, J. Am. Chem. Soc. 2008, 130, 17270; f) B. Wang, B. Lu, Y. Jiang, Y. Zhang, D. Ma, Org. Lett. 2008, 10, 2761; g) L. Li, W. W. Brennessel, W. D. Jones, J. Am. Chem. Soc. 2008, 130, 12414; h) K. M. Allan, B. D. Hong, B. M. Stoltz, Org. Biomol. Chem. 2009, 7, 4960; i) N. Guimond, K. Fagnou, J. Am. Chem. Soc. 2009, 131, 12050; j) T. Fukutani, N. Umeda, K. Hirano, T. Satoh, M. Miura, Chem. Commun. 2009, 5141; k) N. Todorovic, E. Awuah, S. Albu, C. Ozimok, A. Capretta, Org. Lett. 2011, 13, $6180 ; 1)$ Y.-F. Wang, K. K. Toh, J.-Y. Lee, S. Chiba, Angew. Chem. Int. Ed. 2011, 50, 5927; Angew. Chem. 2011, 123, 6049; m) T. Xu, G. Liu, Org. Lett. 2012, 14, 5416; n) R. K. Chinnagolla, S. Pimparkar, M. Jeganmohan, Org. Lett. 2012, 14, 3032; o) J. Jayakumar, K. Parthasarathy, C.-H. Cheng, Angew. Chem. Int. Ed. 2012, 51, 197; Angew. Chem. 2012, 124, 201; p) Z. Shi, D. C. Koester, M. Boultadakis-Arapinis, F. Glorius, J. Am. Chem. Soc. 2013, 135, 12204; q) P. Villuendas, E. P. Urriolabeitia, J. Org. Chem. 2013, 78, 5254

[7] B. S. Pilgrim, A. E. Gatland, C. T. McTernan, P. A. Procopiou, T. J. Donohoe, Org. Lett. 2013, 15, 6190.

[8] a) N. A. Beare, J. F. Hartwig, J. Org. Chem. 2002, 67, 541; b) X. Wang, A. Guram, E. Bunel, G.-Q. Cao, J. R. Allen, M. M. Faul, J. Org. Chem. 2008, 73, 1643.

[9] J. R. McElhanon, T. J. Shepodd (Sandia Corp), US 7449579 B1, 2008.

[10] T. M. Hung, T. M. Ngoc, U. J. Youn, B. S. Min, M. Na, P. T. Thuong, K. Bae, Biol. Pharm. Bull. 2008, 31, 159.

[11] G. R. Lenz, J. Org. Chem. 1977, 42, 1117.

[12] C. Moulis, J. Gleye, E. Stanislas, Phytochemistry 1977, 16, 1283.

[13] J.-K. Lee, J.-G. Cho, M.-C. Song, J.-S. Yoo, D.-Y. Lee, H.-J. Yang, K.-M. Han, D.-H. Kim, Y.-J. Oh, T.-S. Jeong, N.-I. Baek, J. Korean Soc. Appl. Biol. Chem. 2009, 52, 646.

[14] a) H. Liu, X. Xie, X. Zhen, H. Sun, J. Li, L. Zhu, Z. Li, Y. Chen, H. Jiang, K. Chen (Shanghai Institute of Materia Medica, Chinese Academy of Sciences), US 2014/0088130 A1, 2014; b) C. Moulis, E. Stanislas, J.-C. Rossi, Org. Magn. Reson. 1978, 11, 398.

[15] a) M. Hanaoka, S. Yoshida, C. Mukai, Chem. Pharm. Bull. 1989, 37, 3264; b) M. Miyazawa, K. Yoshio, Y. Ishikawa, H. Kameoka, J. Agric. Food Chem. 1998, 46, 1914; c) S. Tong, J. Yan, J. Lou, J. Liq. Chromatogr. Relat. Technol. 2005, 28, 2979.

[16] Z. Kiparissides, R. H. Fichter, J. Poplawski, B. C. Nalliah, D. B. MacLean, Can. J. Chem. 1980, 58, 2770.

[17] a) M. Hanaoka, S. Yoshida, C. Mukai, J. Chem. Soc. Chem. Commun. 1985, 1257; b) K. Iwasa, Y. Kondoh, M. Kamigauchi, $J$. Nat. Prod. 1995, 58, 379.

[18] F. K. Duah， P. D. Owusu, J. E. Knapp, D. J. Slatkin, P. L. Schiff Jr., Planta Med. 1981, 42, 275. 